\title{
PSICOLOGIA DISCURSIVA E O SUJEITO DO CONHECIMENTO: A SINGULARIDADE COMO QUESTÃO
}

\author{
Marina Assis Pinheiro* \\ Luciano R. de Lemos Meira\#
}

\begin{abstract}
RESUMO. Este artigo discute as possibilidades de aplicação da noção de singularidade no contexto da psicologia cognitiva. Investe-se nesta questão porque, dada a diversidade dos fenômenos humanos implicados na construção do conhecimento, é importante sabermos a partir de que condições os sujeitos se diferenciam enquanto intérpretes únicos e quanto a psicologia tem tradicionalmente enfatizado a importância dos fenômenos universais na cognição humana. Para tanto, recorremos ao campo de discussões sobre processos de produção de sentidos como via de acesso à construção da noção de singularidade. $\mathrm{O}$ artigo referenciou-se nas proposições do chamado "segundo Wittgenstein", a fim de subsidiar o diálogo entre a episteme da psicologia discursiva e a abordagem sócio-histórica de Vygotsky. Nosso objetivo foi destacar a importância que o singular pode produzir numa psicologia implicada com a subjetividade discursivamente construída e, ao mesmo tempo, única em sua potência de significação e redescrição de si mesma..
\end{abstract}

Palavras-chave: Singularidade; sentido; psicologia discursiva.

\section{DISCURSIVE PSYCHOLOGY AND THE EPISTEMIC SUBJECT: SINGULARITY AS A QUESTION}

\begin{abstract}
This article discusses the conditions for applying the notion of singularity within the discourse of cognitive psychology. Given the diversity of human phenomena associated with the construction of knowledge, it is important to delineate the conditions by which individuals differentiate themselves as unique interpreters, and how cognitive psychology has traditionally emphasized the importance of universal phenomena in human cognition. In order to access the notion of singularity, we built on studies about the processes of meaning production and used as a reference the propositions of socalled Wittgenstein II. This opened up a dialogue between two distinctive but related episteme -discursive psychology and Vygotsky's sociohistorical psychology-, both at the core of our argument. Our goal was to underline the implications of the singular for discursively-oriented notions of subjectivity in psychology, taking into account the uniqueness of psychology itself as a field for signification and redescription.
\end{abstract}

Key words: Singularity; meaning; discursive psychology.

\section{PSICOLOGÍA DISCURSIVA Y EL SUJETO DEL CONOCIMIENTO: LA SINGULARIDAD COMO CUESTIÓN}

RESUMEN. Este artículo discute las posibilidades de aplicación de la noción de singularidad en el contexto de la psicología cognitiva. Invertimos en este tema, porque, dada la diversidad de los fenómenos implicados en la construcción del conocimiento humano, es importante saber de las condiciones en que los sujetos se diferencian como intérpretes, tanto en la psicología tradicionalmente ha hecho hincapié en la importancia de lo universal en la cognición humana. Para ello, utilizamos el campo de los debates sobre la producción de sentido, como medio de acceso a la construcción de la noción de singularidad. El artículo hace referencia en las propuestas de la llamada segundo Wittgenstein con el fin de apoyar el diálogo entre la episteme de la psicología discursiva y socio-histórica de Vygotsky. Nuestro objetivo es poner de relieve la importancia de la psicología individual puede producir un discurso con la subjetividad y construido al mismo tiempo, única en su significado y el poder de redescription sí mismo.

Palabras-clave: Singularidad; sentido; psicología discursiva.

Psicóloga. Mestre em Psicologia Clínica. Doutoranda em Psicologia Cognitiva pela Universidade Federal de Pernambuco.

\# Pedagogo. Ph. D. em Educação Matemática. Professor Adjunto do Departamento de Psicologia da Universidade Federal de Pernambuco. 
No atual cenário discursivo da Psicologia, a noção de singularidade (do self, da pessoa) tem assumindo destaque crescente nos debates das mais diversas áreas deste campo do saber. Talvez como reflexo da virada linguística nas Ciências Humanas (expressão que demarca a crise dos discursos sustentados numa versão representacionalista e normatizante da relação sujeito-linguagem), a preocupação acerca do lugar do singular nas formas de vida produzidas pelo sujeito epistêmico nunca foi tão referida.

A ênfase sobre o papel do "resto cartesiano" (Guerra \& Carvalho, 2006), as narrativas sobre autoria (Barthes, 2004; Alberti, 1991; Bakhtin, 2003), o individualismo, a psicanálise e a literatura como adventos da modernidade (Foucault, 2002), as éticas da inclusão (Batista, 2004), as muitas pesquisas acerca da relação entre cognição e afetividade (Gomes \& Falcão, 2008), o valor da diferença e do idiossincrático na cultura dos nossos dias (Birman, 1997) e outros incontáveis aspectos tematizados pelas ciências humanas parecem ter arado o solo sobre o qual hoje brotam as práticas discursivas que tocam à questão do singular nas mais variadas correntes de pensamento.

Neste contexto, que possíveis sentidos a noção de singularidade poderia assumir no discurso psicológico-cognitivo? Entendida enquanto dispositivo linguístico que performatiza uma hermenêutica específica da subjetividade, esta noção parece sinalizar para um lugar de certa obscuridade teórica. Assim, a plasticidade de usos do termo singularidade demanda um "tratamento linguístico" de suas delicadas tessituras de significação.

O presente artigo delineia-se como uma investigação dos possíveis diálogos entre autores da chamada psicologia discursiva (e.g., Edwards, 1997) e do argumento acerca da subjetividade proposto por Vygotsky em Psicologia da Arte (1998). A escolha de tais cenários teóricos na interlocução com a questão do singular justifica-se na medida em que estes campos de argumentação sinalizam para um lugar privilegiado da noção de singularidade no contexto da psicologia cognitiva.

Esta tentativa de articulação é trabalho bastante desafiador, tendo-se em vista o domínio da tradição clínico-psicanalítica nos vocabulários sobre o singular e a escassa literatura sobre o tema em psicologia cognitiva, além da enorme diversidade de perspectivas que caracteriza esta última. Sendo assim, o que configura o foco das reflexões oferecidas neste artigo é o redimensionamento da função da diferença radical, da unicidade nas descrições sobre o sujeito (Bakhtin, 1993) ou sobre a psychê. Em síntese, buscamos uma elaboração acerca das possibilidades de abordagem da noção de singularidade à luz dos variados discursos que participam dos debates acerca do sujeito cognoscente. A noção de singularidade, como epistemologicamente é tratada aqui, remete-nos às seguintes questões: não estaria a noção de singularidade relegada a certa obscuridade teórica justamente pelo seu papel dialético em relação ao saber instituído?; consequentemente, não deveríamos guardar esta noção numa zona de irredutibilidade, devido à sua função de matriz para a emergência do novo?; e sendo assim, não seria o estudo sobre o singular uma investigação paradoxal, no sentido em que o objeto seria justamente o espaço de rarefação, de porosidade, o "território de ignorância" (Figueiredo, 2004) propulsor das teorias?

A formulação de repostas prévias a estas questões é descartada neste momento da escrita. $\mathrm{O}$ fechamento em um significado prévio para o singular seria, neste caso, a antirregra da pesquisa sobre os possíveis vocabulários mediadores da construção de um lugar realçado para a noção de singularidade no contexto da psicologia cognitiva ou, mais particularmente, no contexto das formulações sobre o "sujeito cognoscente". Na seção a seguir, começamos a refletir sobre as possibilidades de circulação da noção de singularidade nas concepções sobre os chamados processos cognitivos, antes de passarmos às teorias instrumentalizadoras da discussão sobre o lugar do singular na psicologia cognitiva.

\section{DA MÁQUINA AO DISCURSO}

Os ditos processos cognitivos (a memória, a percepção, a atenção, a consciência, a linguagem e outros), entendidos enquanto dimensões necessárias e fundacionais em relação à construção do conhecimento, se tomados "em si mesmos", isoladamente, enquanto partes ou engrenagens de uma "maquinaria" cognitiva, dificilmente poderiam desenvolver um diálogo efetivo com a questão da singularidade. Metáforas objetivistas do tipo computacional ou cerebralizante da mente, entre possíveis outras, ao subtraírem a questão do sujeito de suas narrativas, considerando-a um obstáculo ou epifenômeno ao entendimento do indivíduo, situam-se num universo radicalmente distinto daquele que orienta o presente ensaio. Num contexto de pretensões discursivas acentuadamente voltadas para os "universais", em que a linguagem é tomada como "espelho da natureza", a noção de singularidade não traria qualquer contribuição efetiva. Seu lugar estaria restrito ao do desvio, do resto. 
O encontro da temática da singularidade com os discursos sobre os processos cognitivos ocorre quando a subjetividade, a contingência histórica do sujeito, a cultura e a linguagem deixam de ser "aspectos" ou "fatores" da cognição e passam a ser condição para a possibilidade de compreensão do sujeito cognoscente (Bruner, 1999).

A chamada psicologia discursiva insere-se criticamente neste debate ao negar a visão cartesiana do indivíduo e assumir as implicações últimas da proposição segundo a qual seria apenas na linguagem, mais especificamente nas práticas discursivas de seus usuários, que qualquer entendimento sobre sujeito-emundo torna-se possível. Isto significa dizer que, para esta e todas as abordagens que propõem uma leitura pragmática do discurso, o sujeito psicológico funda-se nos processos estabelecidos pelos vocabulários de uma determinada cultura.

$\mathrm{O}$ pressuposto epistemológico que inspira a metodologia da psicologia discursiva pauta-se no antiessencialismo do Wittgenstein das Investigações Filosóficas (1958/2004), razão pela qual realizamos, na seção a seguir, uma breve incursão nas principais construções desta filosofia.

\section{PRAGMATISMO LINGUÍSTICO E PSICOLOGIA DISCURSIVA}

As proposições wittgensteinianas, ao se afastarem do cenário objetivista da linguagem, inauguram uma episteme segundo a qual o universo experiencial humano é domínio dos processos de significação de sujeitos contingenciados por contextos interacionais e históricos e pelas formas de vida das quais estes participam.

Demolidor de concepções essencialistas e representacionalistas do sujeito, Wittgenstein (1958/2004) produz uma leitura sobre a linguagem a partir de um lugar inventivamente singular em relação às tradições estruturalistas e designativoinstrumentalistas. Trata-se, ao contrário, da linguagem enquanto forma de vida, caracterizada por um jogo de regras sempre abertas, num permanente devir, pelo qual o dito torna-se passível de semiotização.

A crítica de Wittgenstein aos essencialismos em geral refere-se, sobretudo, à tendência daquelas perspectivas a contemplar expressões linguísticas abstratas, fora do contexto em que surgem (Wittgenstein, 1958/2004). Isto seria um equívoco da mesma natureza que as indagações filosóficas do tipo "o que é?" Perguntas desta natureza buscam a essência de algo, como se em busca de um fantasma. Para Wittgenstein, a análise das essências deveria ser substituída por uma forma linguística de estudo do uso contextual das palavras.

Quem não tem clara a variedade dos jogos de linguagem estará inclinado a fazer perguntas como esta: "O que é uma pergunta?" - É isso a constatação de que não sei tal e tal coisa ou a constatação de que eu desejo que o outro possa me dizer...? Ou é a descrição de meu estado de espírito de incerteza? - E o grito de "Socorro!" é uma descrição? Pense na quantidade de coisas que são chamadas de "descrição" (...) (Wittgenstein, 1958/2004, p. 24)

É neste ponto que Wittgenstein abandona a teorização acerca de uma suposta função designativa da linguagem e passa a colocar seu uso como pedra angular de suas reflexões sobre a produção de sentidos para e com as palavras. De acordo com o acima citado, o próprio ato de pensar, o "ter em mente", darse-ia na e pela linguagem. Isto significa que pensamos, operamos, numa dimensão rigorosamente linguística: "Somente dentro de uma linguagem posso ter em mente algo como algo. Isto mostra claramente que a gramática do 'ter em mente' não é idêntica à da expressão 'representar algo', e coisas do gênero". (Wittgenstein, 1958/2004, p. 38)

Segundo Wittgenstein, se o nosso funcionamento cognitivo ocorresse numa dimensão representacional ou designativo-instrumental, a pessoa que recebesse uma instrução escrita acerca de uma vaca deveria, durante o tempo em que lê o bilhete, preocupar-se em representar a vaca, a fim de não perder o sentido daquilo registrado na escrita (1958/2004, p. 449). Ao contrário, Wittgenstein defende que o aprendido acerca do significado de algo, palavras em particular, seria sempre o entendimento relativo aos seus usos nos possíveis contextos em que elas podem ser adequadamente empregadas.

Nesta perspectiva, conclui-se que o sentido não é um advento ou apêndice ao uso das palavras, muito pelo contrário, o uso é a dimensão pela qual e na qual o sentido se atualiza. Podemos, assim, propor que a inteligibilidade, ou a possibilidade de entendimento num dado campo intersubjetivo, emerge à luz de nossa participação em jogos de linguagem próprios de uma determinada cultura ou forma de vida. Esta noção, que não encontra em Wittgenstein uma definição propriamente dita, aponta, em nossa leitura, para o conceito de práticas culturais, ou seja, as regularidades no campo da ação e dos discursos de um dado grupo social (Meira \& Pinheiro, 2007).

O sentido de uma palavra, expressão, enunciado, conversação ou discurso depende dos processos e das 
disposições linguísticas pelos quais nos tornamos responsáveis no andamento dos jogos de linguagem. Tais jogos emergem na obra do segundo Wittgenstein em oposição à concepção de linguagem como um veículo de representação ou espelhamento do mundo. Jogos de linguagem são apresentados por Wittgenstein como algo resistente a uma descrição exaustiva ou de rígida conceptualização; portanto, se tentarmos definir o que são jogos através da abstração de um conjunto de propriedades comuns e universais entre eles, logo nos frustraremos.

Assim, tal como outras noções em Investigações Filosóficas, a noção de jogos de linguagem é propositadamente desprovida de uma positividade descritiva. Para entender jogos devemos sempre nos orientar pelo caráter de plasticidade, fluidez e ambiguidade das regras ou modos de ação e discurso que são experimentados pelo sujeito como uma trama organizadora e performaticamente inventiva de sua participação em práticas culturais específicas ou, conforme indicado acima, formas de vida.

Edwards (1997) salienta que as regras orientadoras da ação humana não se restringem a situações experimentadas no contexto de uma regência externa (governo), à qual seríamos meramente submissos, ou ao seguimento de prescrições culturalmente acordadas. A partir do paradigma da psicologia discursiva, Edwards sugere que "[seguir regras] depende de como os atores sociais, ao agirem ou descreverem suas ações, tratam as regras como relevantes. Isto envolve o tratamento que os atores dão às regras, enquanto restritivas, ou necessárias, ou inaplicáveis, ou opcionais (...)" (1997, p. 5)

Assim, esse autor salienta a impossibilidade de tais regras serem "descobertas" por análises objetivas, uma vez que elas se encontrariam na contingência das ações realizadas pelos sujeitos, realizações cujas regras muitas vezes acontecem como registro intuitivo da situação. De fato, tudo isto depende fortemente de como as coisas e os eventos são descritos, pois não existem regras que deem conta de todas as contingências e aplicações. Ao contrário, regras são atualizadas, reinventadas ou realçadas de acordo com a especificidade dos contextos experienciados pelos sujeitos e da forma como eles descrevem tais experiências.

Destarte, seria a partir dos usos ordinários da linguagem, de nossas práticas discursivas no mundo, que poderíamos falar da constituição da subjetividade. Isso significa que, para o pragmatismo filosófico de Wittgenstein e para a psicologia discursiva de Edwards, a função ativa do sujeito usuário dos sistemas simbólicos de dada comunidade é o ponto que demarca um redimensionamento dos indivíduos a partir de suas contingências singularizantes. Nós somos aquilo que as linguagens, os discursos, nos permitem ser; e é porque somos atravessados pelas mais diversas formações simbólicas, de inerradicável polissemia, que nos reconhecemos e nos diferenciamos uns dos outros.

\section{SENTIDO E SINGULARIDADE}

A singularidade se apresenta enquanto noção que adjetiva os sentidos produzidos na especificidade dos múltiplos contextos discursivos que nos atravessam e em relação aos quais somos permanentes intérpretes. Desta forma, não faria sentido falar na singularidade enquanto uma espécie de atributo individual. $\mathrm{O}$ singular seria da ordem da unicidade temporal e discursiva dos sentidos que performatizam seus próprios autores.

Um cenário ilustrativo da construção acima apresentada envolve a questão da cognição dos bebês. Apesar de sujeitos da linguagem, pois inseridos na alteridade discursiva do outro (da mãe), de fato não podemos afirmar que os bebês são sujeitos-autores da produção de um discurso próprio. Sabemos que há em Psicologia um vasto campo de pesquisas que, a partir das mais diversas epistemologias, buscam esclarecer os enigmas de um momento tão primevo da constituição, com base em estudos experimentais sobre aspectos como intenções, atenção, memória e outros (Meltzof, 1995). Para nós, entretanto, a relevância deste tema não está nos resultados em si de tais pesquisas, e sim, na forma como este campo de interpretação reflete as dinâmicas discursivas que participam dos processos de subjetivação.

No tocante aos comportamentos dos bebês, afirmam Edwards (1997) e Costa (2001) que as questões acerca da mente infantil não deveriam enfocar uma suposta correspondência entre as reações da criança e seus sentidos "pré-linguísticos" (como quando as mães identificam vontades e intenções no infante), mas sim, as descrições produzidas pelo olhar do observador ou cuidador e os sentidos por ele atribuídos a essas reações. Para estes autores, são estas práticas discursivas, estas significações, que, pelo jogo de alteridades, produzem a subjetividade das díades. $\mathrm{O}$ bebê torna-se um usuário competente da linguagem apenas a partir destes vocábulos herdados, os quais viabilizam a interação adulto-criança; por sua vez, seriam estes mesmos sentidos que permitiriam uma diferenciação na condição daqueles que leem (interpretam) estas ou aquelas experiências no bebê. 
O ideal que inspiraria esta forma de entendimento dos processos de subjetivação encontra em Costa (1994) a seguinte formulação, denominada de "ideal do autoenriquecimento":

Este ideal pode ser razoavelmente formulado pela máxima pragmática que diz: "não me pergunte o que realmente sou'; "qual meu verdadeiro eu"; "o que de essencial existe em mim". Pergunte, "como posso redescreverme, de maneira a viver uma vida melhor ou mais bela (...)". O sujeito que se descreve a partir deste ideal esforça-se por imaginar como novas descrições podem reorientar, de um modo mais satisfatório, aquilo que vive como insatisfação, mal-estar, angústia, medo, desespero, sofrimento ou simples vontade de expandir a capacidade de ser feliz. (p. 21)

Enfatiza-se, nesta perspectiva, a constituição psíquica como um constructo produzido por recorrências histórico-discursivas nas quais o passado é constantemente reinventado à luz da atualidade discursiva do sujeito. Seriam as narrativas, as significações que produzimos a cada momento de nossa existência, que comporiam a argamassa singular daqueles que reconhecemos como "nós mesmos" ou como um "eu". Em outras palavras, nossa história darse-ia num "modo de descrever esse passado, modo este que o próprio passado jamais conheceu" (Rorty, 2007, p. 67). É desta posição que o singular é forjado: da infinita possibilidade de redescrição dos discursos que nos atravessam e nos constituem enquanto sujeitos participantes de uma cultura.

Por outro lado, Harré e Gillet (1999) associam a mente do indivíduo a "uma mera conexão ou ponto de encontro das relações sociais" (p. 26). De acordo com estes autores, a mente (enquanto uma construção social) é, na expressão de sua narrativa, "moldada" por conceitos estabelecidos nas práticas discursivas culturais. Esta formulação não seria problemática se assumíssemos a subjetividade como um conjunto uniforme de semelhanças e identidades. Neste argumento, a diferença, a alteridade, as assimetrias, têm apenas a função de resto das relações sociais.

Acreditamos, não obstante, que os construtos de mente como ponto de encontro e da diferença como resto social não são plausíveis. Ao observarmos situações de conversação cotidiana (ou a escrita de um artigo científico), por exemplo, avaliamos como bastante notável o esforço do falante (ou autor) em fazer "convergir" os sentidos de sua fala ao entendimento de seus pares, de aproximar, convencer os interlocutores do universo montado em sua narrativa, processo que implica, conforme a familiaridade e a história relacional destes, em maior ou menor recurso às abreviações no discurso.

Isso posto, em que medida podemos afirmar a qualia dos "pontos de encontro" do argumento de Harré e Gillet (1999)? Para o Wittgenstein das Investigações, é impossível erradicar a ambiguidade das palavras: tudo de que dispomos na linguagem são semelhanças de família. Exemplificando esta noção com o conceito de número, Wittgenstein indaga: "Por que chamamos algo de 'número'? Ora talvez porque tem um direto parentesco com alguma coisa que até agora se chamou de número." (1958/2004, p. 67) Recorrendo, então, à metáfora da tessitura de um fio, Wittgenstein sugere que sua robustez não se daria pela extensão de uma única fibra, mas pela sobreposição de muitas fibras umas às outras. Podemos interpretar a sobreposição aludida a uma espécie de descontinuidade entre os possíveis sentidos relacionados aos conceitos por um jogo aprendido, um jogo de semelhanças; portanto, nesta representação wittgensteiniana não é por meio de encontros semânticos que se daria o emprego de um vocabulário qualquer (o vocabulário dos números, por exemplo), não haveria uma homonímia estabelecida no vocabulário e o princípio da identidade seria uma falácia. Mas, tudo que poderíamos afirmar seriam possíveis semelhanças, como as existentes entre pessoas de uma mesma família - de traços, da forma de andar, de aspectos do temperamento.

\section{CIÊNCIAS COGNITIVAS E SINGULARIDADE}

Cornejo (2004), em artigo intitulado "Quem diz o que as palavras dizem? O problema do sentido linguístico em Psicologia", retoma o debate acerca das leituras referentes ao processo de significação na psicologia cognitiva e das tensões entre objetivismo e subjetivismo. Assim como introduz o título do artigo, "quem" (sujeito) diz "o que" (referente, estrutura) significam as palavras é impasse clássico no discurso da psicologia cognitiva. As implicações e entraves entre descrever o significado enquanto experiência subjetiva ou enquanto sentidos que independem do sujeito constituem o mérito da argumentação do referido autor neste artigo. Em suas palavras:

Por um lado, a psicologia cognitiva afirma que existem significados objetivos associados a construções linguísticas, que são, por definição, independentes do sujeito. Por outro, a psicologia cognitiva também propõe que o significado de expressões linguísticas é o resultado de um processo 
interpretativo e construtivo realizado pelo falante/ouvinte, do qual o significado não é, portanto, independente. Assim, significados linguísticos tornam-se ao mesmo tempo dependentes e independentes do sujeito. (Cornejo, 2004, p. 7)

Os modos de entendimento dos processos de significação, conforme já citado, constituem um ponto crucial no estudo da singularidade. Esta temática remonta ao lugar que a subjetividade e, consequentemente, a singularidade desempenham nas concepções sobre a mente. Os processos de significação seriam, em psicologia, uma via de acesso à compreensão de como a existência é ou torna-se singularizada pelo sujeito.

A natureza quasipsicológica da pragmática (Cornejo, 2004, p. 12), ao desconstruir a ideia segundo a qual o significado das palavras poderia ser encontrado na "essência delas mesmas" (meaning in itself), reafirma a radicalidade do caráter intersubjetivo do processo de significação (Bezerra \& Meira, 2006). Os significados decorrem, assim, de processos contingentes aos contextos de uso das palavras; contextos dialógicos em que as palavras significam enquanto "significado para alguém" (meaning for somebody). Nas palavras de Cornejo (2004): "Quando consideramos o contexto de uso de uma expressão particular, estamos nos referindo não a um 'significado em si mesmo', mas, pelo contrário, à experiência subjetiva de significação". (p. 12)

Por outro lado, se concebermos a produção de sentidos como uma experiência subjetiva - em oposição a uma concepção de significação enquanto processo objetivo e compartilhado (pelas convenções sociais) - estaremos, à primeira vista, assumindo num mesmo plano duas entidades supostamente dicotômicas e excludentes: o social e o individual, idiossincrático.

De acordo com Cornejo (2004), o acima exposto é um pseudoimpasse, que se dilui pela suposição de uma subjetividade que não é anterior, nem à parte, muito menos existente em si mesma, em relação ao Outro social. É através da linguagem e dos signos socialmente compartilhados que nos tornamos sujeitos, ao mesmo tempo em que a partir de sua polissemia desenvolvemos o traço da apreensão singular sobre a nossa realidade. A linguagem, neste sentido, ratifica a natureza alteritária da constituição humana.

Neste caso, podemos falar de singularidade discursivamente sobredeterminada. Isto significa dizer que os processos de singularização dão-se na medida em que o sujeito, através de uma linguagem - composta que é por signos compartilhados pela cultura - significa e transforma a si mesmo, a sua própria história, a sua própria contingência corporal, fisiológica, organísmica e cultural.

\section{PSICOLOGIA DISCURSIVA E A ABORDAGEM SOCIO-HISTÓRICA DE VYGOTSKY}

$\mathrm{Na}$ perspectiva sócio-histórica a noção de singularidade pode ser elaborada a partir da seguinte questão, proposta por Valsiner e Van der Veer (2000):

Como conceber as pessoas enquanto sociais sem abandonar sua óbvia autonomia pessoal, sua separação de qualquer unidade social (grupo, multidão, comunidade), ainda que membros de tais unidades? (p. 6)

Nitidamente preocupados com a manutenção da complexidade humana na teorização em ciências humanas e criticamente atentos aos reducionismos e aplicativismos de fundo sociológico, os referidos autores argumentam sobre a dificuldade de quebra do raciocínio do tipo "isso ou aquilo", em oposição a "isso $e$ aquilo ao mesmo tempo", na cultura psicológica. Valsiner e Van der Veer (2000) propõem que uma saída para o modelo exclusivista e tautológico das causalidades humanas ocorre entre os pesquisadores contemporâneos da abordagem sociocultural ao refletirem, de modo verticalizado, sobre as implicações epistêmicas de conceitos como internalização/externalização, apropriação, ou ainda, no vocabulário sociogenético de James Mark Baldwin, separação inclusiva. O debate atual sobre noções como estas apontaria para o esforço de superação dos modelos clássicos, bem como para a tentativa de manter a condição social do ser humano sem abrir mão da dimensão idiossincrática das individualidades. De fato, como argumenta Cornejo (2004), "Em décadas recentes, entretanto, a psicologia tem se aproximado de uma perspectiva sócio-cultural acerca dos processos mentais que é consideravelmente diferente do conceito de mente que foi objeto da crítica anti-psicológica no século 19.” (p. 18)

Para Hacker (2000), a dialética do interno e externo - que aparenta subsidiar muitos dos construtos vygotskianos - é, originalmente, consequência de uma tradição mentalista-representacional, fundada numa metafísica localizacionista que contradiz o próprio Vygotsky, quando sugere o papel da linguagem como campo de mediação performatizante do sujeito.

Onde, de que modo ou por meio de que "alquimia" histórico-discursivista torna-se possível 
situar uma internalidade distinta da argamassa linguística das práticas culturais de uma suposta exterioridade? Através de que dispositivos linguísticos seria possível imaginar uma dimensão outra para o singular que não situada na gramática do interno? Não seria mais pertinente pensarmos, como sugere a abordagem discursivo-pragmatista, em experiências públicas ou privadas? Esta questão se oferece como uma alternativa à herança cartesiana do internoexterno, e pode ser formulada nos seguintes termos:

Os mecanismos das mentes individuais estão disponíveis a nós naquilo que criamos conjuntamente em nossas conversas e, se nossa atividade mental privada também é simbólica, então podemos torná-la disponível ou não, conforme a situação pareça exigir, usando basicamente o mesmo sistema. (Harré \& Gillet, 1999, p. 30)

Destarte, o mundo mental inclui necessariamente a "argamassa linguística" que podemos compartilhar quando escolhemos ou somos de alguma forma compelidos a fazê-lo. Quando, então, efetivamente publicamos aspectos de nossa atividade privada/interior, fazemo-lo pela linguagem em situações interacionais específicas, nas quais há uma conversação em curso e outros atores sociais identificáveis como pessoas são capazes de estabelecer relações de reciprocidade, presenciais ou à distância, síncronas ou assíncronas, mas sempre na forma de diálogo (Marcuschi, 2003); ou, de forma mais ampla, em contextos dialógicos não necessariamente interacionais, nos quais os interlocutores/destinatários são pressupostos - como, por exemplo, a audiência de um texto científico ou romance que seja responsiva aos argumentos do autorcriador ou aos clamores do herói, mediante uma interlocução com a obra sem que se estabeleçam relações de reciprocidade baseadas na conversação com o autor-pessoa) (Bakhtin, 1987). Nesta concepção, não faz sentido supor na mente um universo à parte, extralinguístico, como um reservatório de experiências inacessíveis. Aquilo que aprendemos como interno ou externo é uma metáfora forte, produzida por um jogo de linguagem que vemos como insatisfatório quando nos deparamos com a fragilidade da diferenciação destas duas supostas dimensões subjetivas. Este debate retorna, por sua vez, à pseudo-oposição entre objetivismo e subjetivismo, já argumentada neste artigo.

Por outro lado, Edwards (1997) ressalta os méritos da formulação vygotskiana acerca dos processos de subjetivação nos seguintes termos: “Um importante e proeminente aspecto da psicologia de Vygotsky é que o todo da cultura, na formação da mente, não é meramente um fator causal disposto em variáveis, nem uma 'influência' do contexto social nos processos e conteúdos mentais. A relação é muito mais fundamental." (p. 44)

Neste sentido, Edwards convoca um diálogo entre a perspectiva da psicologia discursiva e o materialismo sócio-histórico de Vygotsky, uma vez que ambas as abordagens compartilham da dimensão constitutiva da linguagem, à luz do estudo das ações humanas, enquanto práticas reconceitualizadoras da relação sujeito-mundo. Caberia, não obstante, indagar em que medida as noções vygotskianas de "mediação simbólica", enquanto ferramenta psicológica, efetivamente dialogam com o cenário discursivopragmatista de inspiração wittgensteiniana.

Podemos estabelecer aproximações entre as perspectivas supracitadas a partir do compartilhamento, que ambas guardam, acerca da função da cultura, dos contextos pragmáticos da ação, de um sujeito constituído na linguagem. Podemos, ainda, entender a aproximação destes dois campos (a psicologia discursiva e a teoria de Vygotsky) em termos de semelhanças de família; mas podemos também apontar na direção das diferenças entre estas duas abordagens, por exemplo, na relação que a noção de "mediação" guarda com a suposição linguística da referenciação. Em seu Manuscrito, Vygotsky propõe acerca do desenvolvimento infantil:

Daí é possível acompanhar, passo a passo, na criança esta mudança em si, para os outros, para si nas funções da fala. Antes de tudo a palavra deve possuir sentido (relação com as coisas) em si (ligação objetiva, e sem ela não existe - não há nada); depois a mãe a usa funcionalmente como palavra; depois - a criança. (2000, p. 25)

Assim, o suposto referencialismo vygotskiano assume um sentido muito especial, i.e., o de um momento no processo de constituição do sujeito da linguagem. Se observarmos o uso da linguagem que as crianças fazem dos dois aos seis anos de idade, veremos que as palavras são mais frequentemente utilizadas como nomes, indissociáveis do objeto ao qual elas são destinadas.

Por meio do processo aludido na citação acima, Vygotsky formulou a chamada lei geral das funções psicológicas superiores. Esta formulação viria a dar conta da suposição deste autor segundo a qual, no desenvolvimento cultural da criança, qualquer função emerge em duas cenas, das quais a primeira é social, 
interpsicológica, e a segunda, psicológica, intrapsíquica. Neste desenho, "o individual, o pessoal - não é 'contra', mas uma forma superior de sociabilidade.” (Vigotsky, 2000, p. 27)

Destaca-se, assim, que a questão do sentido de objetividade na obra de Vygotsky pode ser afeita a muitos mal-entendidos. Apesar da tradicional acepção deste termo, o que é designado por objetivo na teoria culturalista é marcado pela função dos signos enquanto produtores do próprio artefato. Assim, tal qual encontramos no método da dupla estimulação, em que a criança se depara com uma situação que excede suas possibilidades de entendimento, temos a figura do experimentador (ou artefato) como um mediador, de função ativa no processo de construção de estratégias da criança para a resolução da situação. Seria de uma cognição compartilhada dialogicamente, desde suas origens, que Vygotsky trata em seus escritos. Assim, o sentido de objetividade que permeia a obra deste autor situa-se num entendimento desta em termos de uma realidade compartilhada através da linguagem. Esta concepção faz lembrar a seguinte passagem dos escritos pragmatistas de Rorty: "O mundo em si sem o auxílio das atividades descritivas dos seres humanos - não pode sê-lo." (2007, p. 28)

Talvez, por caminhos distintos, a psicologia discursiva e a abordagem sócio-histórica de Vygotsky tenham encontrado uma aproximação que alimenta questões semelhantes em ambas. Colocada a questão de forma sucinta, para a psicologia discursiva, que se ergue do esforço em fazer uma narrativa acerca da subjetividade a partir de uma filosofia da linguagem, a teoria culturalista pode contribuir com as especificidades psicológicas deste sujeito constituído na e pela linguagem. Para a abordagem vygotskiana, a perspectiva discursiva pode redescrever certas problemáticas teóricas, como a questão da externalidade/internalidade, e contribuir na reflexão acerca do lugar da performatividade da linguagem na produção de métodos de investigação psicológica.

Sem a pretensão de contemplar aqui toda a complexidade polissêmica de Psicologia da Arte (Vygotsky, 1998), entendemos que esta obra parece superar alguns destes entraves e acrescentar uma perspectiva importante à temática da singularidade. Embora pouco citados, os escritos ali reunidos apresentam a inquietação do autor quanto a construir um método de análise da produção artística sem recair em psicologismos elementarista-experimentais, nem em reduções metafísicas e especulativas. A problemática das abordagens estéticas é retomada, sendo o materialismo histórico a tendência sociológica que, na visão do autor, apresenta maior "avanço" e "coerência" (p. 9).

No primeiro capítulo dessa obra, intitulado $O$ problema psicológico da arte, Vygotsky, empenhado na construção de um método objetivo-analítico, assim problematiza a especificidade das dimensões sociológicas e psicológicas no contexto das artes:

Seria, entretanto, superficial afirmar que a arte não dispõe de lei própria de desenvolvimento. Um fluxo d'água é determinado pelo seu leito e suas margens [...] por mais que a correnteza de um regato seja determinada pela férrea necessidade das condições externas, ainda assim a sua essência é determinada pelas leis da hidrodinâmica, leis que não podemos apreender das condições externas do fluxo, mas tão-somente do conhecimento da própria água. (Vygotsky, 1998, p. 9)

Tomando esta construção como enredo do texto, tem-se que o "conhecimento da própria água", das leis hidrodinâmicas, é indissolúvel em relação às "condições externas". Para Vygotsky, conforme já abordado, o psíquico, o individual, seria constituído pelas relações intersubjetivas, "externas" em sua gramática. "E, sendo assim, Freud teve toda razão ao afirmar que 'a psicologia individual, desde o início, é ao mesmo tempo uma psicologia social.” (Vygotsky, 1998, p. 17). Daí que toda psicologia seria, em suas palavras, uma psicologia do indivíduo particular $e$ concreto, e não haveria nenhum outro psiquismo.

É neste sentido que se investe na importância da discussão acerca dos possíveis sentidos de singularidade. Mediante uma incursão discursivista desde a tradição pragmatista da linguagem até as contribuições vygotskianas sobre a subjetividade, pretendeu-se estabelecer uma problematização sobre o lugar do singular no estudo sobre os processos de significação. Acredita-se que é neste cenário teórico que se torna possível o vislumbramento desta noção no contexto da psicologia cognitiva.

\section{CONSIDERAÇÕES FINAIS}

Este artigo pretendeu desenvolver uma discussão acerca dos possíveis sentidos que a singularidade pode assumir na psicologia cognitiva. A partir de um diálogo entre a abordagem sócio-histórica e a psicologia discursiva, realizou-se uma reflexão sobre os lugares e os efeitos que a referida noção pode promover nos debates sobre subjetividade e linguagem. Nosso objetivo foi destacar, ainda que de 
modo preliminar, a importância que o singular pode produzir numa psicologia implicada com a subjetividade discursivamente constituída e, ao mesmo tempo, única em sua potência de significação e redescrição de si mesma.

Investe-se nesta questão porque a psicologia cognitiva por muito tempo esteve voltada à dimensão estritamente generalizante dos fenômenos. Acredita-se que, por uma diversidade de aspectos teóricos e epistemológicos discutidos neste artigo, é momento de este campo de estudos, a exemplo do que fizeram as ciências clínicas, eleger o singular e a singularidade como condição relevante nos debates sobre o sujeito cognoscente.

Enquanto linha de pesquisa, a singularidade pode encampar uma infinidade de fenômenos altamente responsivos a temas tais como a aprendizagem entre crianças com necessidades "especiais", a construção de "si mesmo", as relações entre afetividade e produção do conhecimento. É enquanto uma escrita germinal a estes temas que o presente ensaio é apresentado ao leitor, na expectativa de promover ressonâncias mais amplas e pragmáticas.

\section{REFERÊNCIAS}

Alberti, V. (1991). Literatura e autobiografia: A questão do sujeito na narrativa. Estudos Históricos, 4(7): 66-81.

Barthes, R. (2004). O rumor da língua. São Paulo: Martins Fontes.

Batista, M. (2004). Ética da inclusão. Belo Horizonte: Armazém das Ideias.

Bezerra, H. \& Meira, L. (2006). Zona de Desenvolvimento Proximal: interfaces com os processos de intersubjetivação. Em L. Meira \& A. G. Spinillo (orgs.), Psicologia Cognitiva: cultura, desenvolvimento e aprendizagem (pp. 188-219). Recife: Editora Universitária UFPE.

Birman, J. (1997). Estilo, modernidade e psicanálise. São Paulo: Editora 34.

Bruner, J. (1999). Atos de significação. Porto Alegre: Artes Médicas.

Bakhtin, M. (2003). Estética da criação verbal. São Paulo: Martins Fontes.

Bakhtin, M. (1993). Por uma filosofia do ato. Austin: University of Texas Press.

Bakhtin, M. (1987). Marxismo e filosofia da linguagem. Petrópolis: Vozes.

Cornejo, C. (2004). Who says what the words say? The problem of linguistic meaning in Psychology. Theory and Psychology, 14(1): 5-28.
Costa, J. (2001). A questão do sentido em Psicanálise. Em B. Bezerra \& C. (Org.), Corpo, afeto e linguagem: A questão do sentido hoje (pp. 199-218). Rio de Janeiro: Rios Ambiciosos.

Costa, J. (1994). Pragmática e processo psicanalítico: Freud, Wittgenstein, Davidson, Rorty. Em J. F. Costa (Org.), Redescrições da Psicanálise: Ensaios pragmáticos (pp. 9-60). Rio de Janeiro: Relumé-Dumará.

Edwards, D. (1997). Discourse and cognition. London: Sage Publications.

Figueiredo, L. C. (2004). Revisitando as psicologias: Da epistemologia à ética das práticas e discursos psicológicos. Petrópolis: Vozes.

Foucault, M. (2002). As palavras e as coisas. São Paulo: Martins Fontes.

Gomes, C. A. \& Da Rocha Falcão, J. T. (2008). Cognição, afetividade, subjetividade: Analisando a construção de significados na sala-de-aula de matemática. Em L. Leão \& M. Correia (Org.), Psicologia Cognitiva: Construção de significados em diferentes contextos (pp. 108-138). Campinas: Editora Alínea.

Guerra, A. \& Carvalho, G. (2006). A singularidade como efeito da relação: Um lugar de equívoco. Rio de Janeiro: Garamond.

Hacker, P. (2000). Wittgenstein: Sobre a natureza humana. São Paulo: Editora UNESP.

Harré, R. \& Gillet, G. (1999). A mente discursiva. Porto Alegre: Artmed.

Marcuschi, L. A. (2003). Análise da Conversação. São Paulo: Ática.

Meira, L. \& Pinheiro, M. A. (2007). Produção de sentidos no uso que se faz de gráficos. Estudos de Psicologia (Natal), 12:135152.

Meltzof, A. N. (1995). Understanding the intentions of others: Reenactment of intended acts by 18-month-old children. Developmental Psychology, 31(5): 838-850.

Rorty, R. (2007). Contingência, ironia e solidariedade. São Paulo: Martins Fontes.

Valsiner, J. \& Van der Veer, R. (2000). The social mind: Construction of the idea. Cambridge: Cambridge University Press.

Vigotsky, L. (2000). Manuscrito de 1929. Educação \& Sociedade (Campinas), 21(71): 21-44.

Vygotsky, L. (1998). Psicologia da Arte. Porto Alegre: Artmed.

Wittgenstein, L. (1958/2004). Investigações filosóficas. Petrópolis: Vozes.

Recebido em 06/07/2009 Aceito em 11/05/2010
Endereço para correspondência:

Marina Assis Pinheiro. Pós-Graduação em Psicologia Cognitiva. Universidade Federal de Pernambuco/CFCH, $8^{\circ}$ andar. Av. Acadêmico Hélio Ramos, s/n, Cidade Universitária, CEP 50670-901, Recife-PE, Brasil. E-mail: marinaassis.pinheiro@ gmail.com. 